\title{
A MODEL FOR SORTED PATTERNED-GROUND REGULARITY
}

\author{
By R. J. RAY, W. B. KRANTZ,
}

(Department of Chemical Engineering, University of Colorado, Boulder, Colorado 80309, U.S.A.)

T. N. CAINE,

(Institute of Arctic and Alpine Research, and Department of Geography, University of Colorado, Boulder, Colorado 80309, U.S.A.)

and R. D. GUNN

(Department of Chemical Engineering, University of Wyoming, Laramie, Wyoming 82071, U.S.A.)

\begin{abstract}
AвSTRACT. Sorted patterned ground refers to polygons, nets, or stripes defined by rocky borders which are the result of sorting in soil subjected to frost action. This paper presents a model in which convection cells, driven by unstable density stratification in the aqueous phase, result in uneven melting of the underlying ice front during thawing. The resulting undulatory ice front with regularly spaced peaks and troughs provides the pattern which results in the regularity observed for certain types of patterned ground. In addition, the model predicts the width to depth-of-sorting ratio for both polygons and stripes, and explains the characteristic hexagonal shape of sorted polygons, the transition from sorted polygons to sorted stripes on sloped terrain, and the formation of sorted polygons under water. The predicted ratio of width to depth-of-sorting of 3.81 for sorted polygons is compared with the ratio of width to depth-of-sorting of 3.57 found from a linear regression analysis of 18 field study data.
\end{abstract}

RÉSUMÉ. Un modèle pour la régularité des sols à réseaux d'éléments triés. Les sols à réseaux d'éléments triés forment des polygones, des réseaux ou des rubans délimités par des limites de pierres qui sont le résultat du trie dans les sols sujets à l'action du gel. Cet article présente un modèle dans lequel des cellules de convection produites par une stratification instable par densité en phase aqueuse, provoque une fusion inégale du front de glace sousjacent pendant la période de fusion. Le front de glace ondulant qui en résulte avec des pics et des creux régulièrement espacés produit le motif régulier observé dans certains types de sols à réseaux. De plus, le modèle prévoit le rapport entre la largeur et la profondeur de tri à la fois pour les polygones et les bandes, et explique la forme hexagonale caractéristique des polygones triés, la transition entre les polygones triés et les bandes trièes sur les terrains en pente, ainsi que la formation sous l'eau de polygones triés. Le rapport prévu de 3,81 entre la largeur et la profondeur de tri pour les polygones triès est comparée avec le rapport de 3,57 entre la largeur et la profondeur de tri trouvées d'une analyse par régression linéaire de 18 données d'études sur le terrain.

Zusammenfassung. Ein Modell für die Regelmässigkeit sortierter Musterböden. Unter sortierten Musterböden sind Polygone, Netzwerke oder Streifen, markiert durch Säume groben Gerölls, die durch Frostsortierung im Boden gebildet werden, zu verstehen. Diese Arbeit entwickelt ein Modell, in dem Konvektionszellen, hervorgerufen durch eine instabile Dichteschichtung in der Auftauphase, zu ungleichmässigem Schmelzen der Permafroststirn während der jahreszeitlichen Tauperiode führen. Die daraus resultierende gewellte Eisstirn mit regelmässig angeordneten Wällen und Trögen liefert das Muster, woraus die Regelmässigkeit entsteht, die bei bestimmten Typen von Musterböden zu beobachten ist. Ausserdem sagt das Modell das Verhältnis zwischen Weite und Tiefe der Sortierung sowohl für Polygone wie für Streifen voraus und erklärt die charakteristische hexagonale Form der Sortierten Polygone, den Übergang von sortierten Polygonen zu sortierten Streifen auf geneigtem Gelände und die Bildung von sortierten Polygonen unter Wasser. Das vorhergesagte Verhältnis von 3,81 zwischen Weite und Tiefe der Sortierung bei Polygonen wird mit dem entsprechenden Verhältnis von 3,57 verglichen, das sich aus einer linearen Regressionsanalyse der Daten von 18 Feldstudien ergab.

THE striking regularity of patterned ground has excited scientific interest for more than a hundred years. Scientists have proposed many hypotheses over the years to explain the origin of 


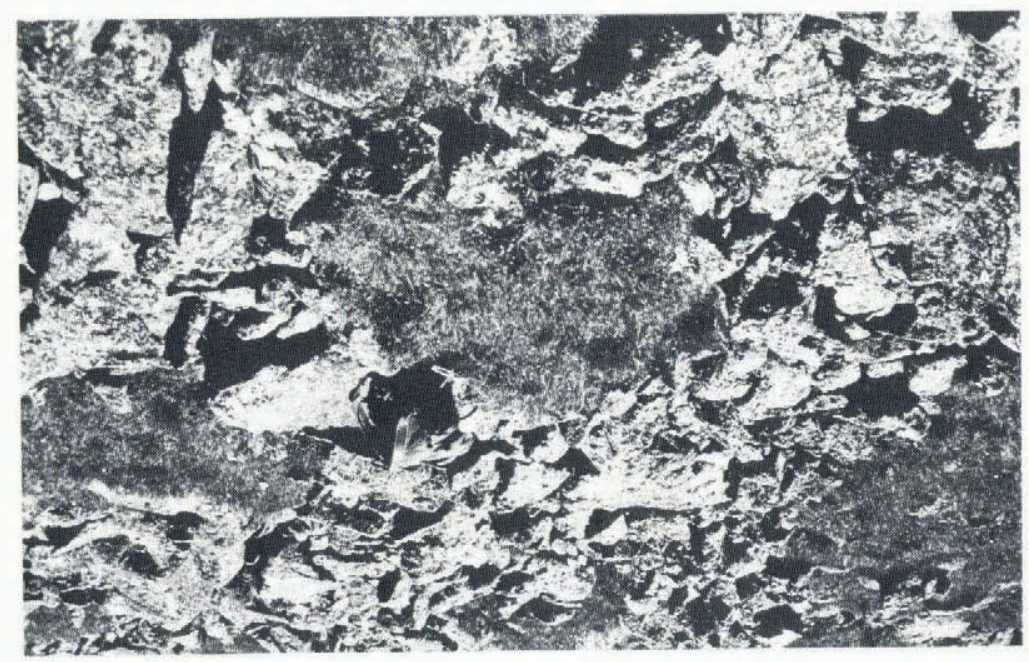

Fig. 1. Relict sorted polygon, Arapaho Pass, Front Range of Colorado. Polygon is approximately 3 m across.

these beautifully symmetrical structures, yet none has been fully satisfactory. Despite a century of investigation, sorted polygons are not well understood; in particular, the reasons for the symmetry and regularity are unknown. The best examples of patterned ground, such as those shown in Figures 1 and 2, lie in remote locations above timber line in the highest mountains of the temperate zone or beyond the tree line in the high Arctic. Here, the impressive regularity of polygonal sorting may extend over several square kilometers at a single site (Richmond, 1949).

Sorted polygons, the type of patterned ground considered in this work, are defined by Matthews and Boyer (1976, p. 399) as “....patterned ground whose mesh is dominantly polygonal and has a sorted appearance commonly due to a border of stones surrounding finer

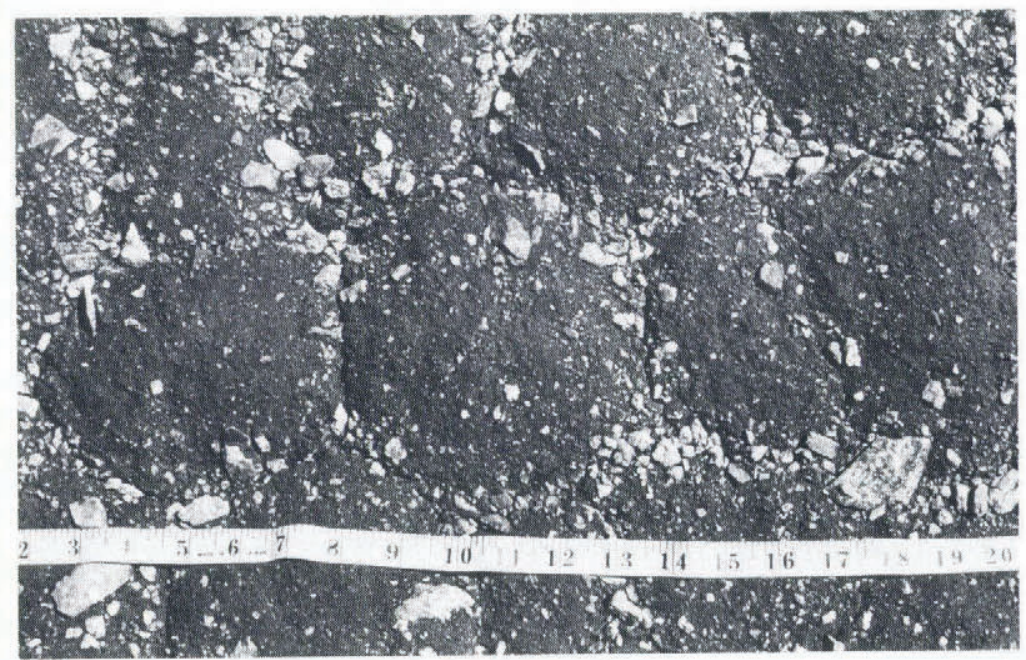

Fig. 2. Photograph of hexagonal, diurnal sorted polygons. 
material (at the center)". The soil inside the polygonal stone borders may be overgrown with grass or other plants; such polygons are believed to be inactive or relict patterns formed during colder epochs in the past. If the soil centers of the polygons are not covered with vegetation, they may still be in an active process of sorting. The diameter of sorted polygons may vary from 0.1 to $10 \mathrm{~m}$ (Washburn, [ [ 1979 ], p. 142). The types of sorted polygons studied here are associated with a periglacial environment. Accordingly, the lower elevation limit for the occurrence of these ranges from sea-level in the Arctic to as high as $5000 \mathrm{~m}$ in middle latitudes (Washburn, $\left[{ }^{\mathrm{c}} 1979\right]$, p. 121). Adequate freeze-thaw cycles are also important in patterned-ground formation. Thus, its formation is often inhibited by perennial snow cover or overlying vegetation.

A full explanation of the formation of sorted polygons may soon be complete as several separate lines of investigation fall into place. It is generally agreed that the origin of patterned ground is polygenetic (Caine, 1972). Washburn (1956) has reviewed several mechanisms - cryostatic pressure, differential frost heave, and primary frost sorting — which can cause a homogeneous mixture of small and large stones to become sorted or segregated through frost action. Some of these mechanisms have recently been demonstrated under controlled laboratory conditions. The missing information has always been a fully convincing hypothesis to explain the regularity, size, and shape of patterned ground. The purpose of this work is to develop a model which does explain the regularity and which can be quantitatively verified with field measurements of sorted polygons.

\section{LITERATURE REVIEW}

Two excellent monographs (Price, 1972; Washburn [ ${ }^{\mathrm{C}}$ 1979] review the extensive literature on patterned ground; therefore, only a brief review of past work is given here. Popular models for patterned-ground formation can be divided into those in which cracking is essential and those in which it is not required. Desiccation cracking, seasonal frost cracking, and permafrost cracking are likely causes of the regularity in some patterned ground forms (Washburn [ $\left.{ }^{c} 1979\right]$, p. 161). The sorting would then be a secondary mechanism, following the development of the crack networks (Washburn [ ${ }^{\mathrm{c}}$ 1979], p. 159).

Cracking processes do occur in Nature, although they are inadequate to explain the regularity and geometry of all sorted patterned ground forms. For example, there are significant differences between the size of the networks formed by cracking processes and that observed for most sorted polygons. Permafrost crack networks are typically an order of magnitude larger than most sorted polygons. Desiccation crack systems, on the other hand, are smaller than most forms (Washburn, [' 1979$]$, p. 161). Also, cracking mechanisms cannot adequately explain the increase in sorted polygon diameter with depth as observed by Meinardus (1912 cited by Washburn, [ $\left.{ }^{c} 1979\right]$, p. 143), nor can they explain the transition from sorted polygons to sorted stripes as the slope steepens, the increase in depth-of-sorting with depth of the active layer, or the regularity of polygon networks.

The hypotheses not involving cracking for patterned ground involve processes such as cryostatic pressure, differential frost heave, and primary frost sorting (Washburn, 1956). These processes also occur in periglacial environments and may well constitute a stage in patternedground formation. However, each of these hypotheses requires an initial regularity of some kind to be present or developed in the soil prior to sorting. A source of such regularity is described by the model presented here. 
This model is derived from linear stability theory which is used in the analysis of potentially unstable systems to determine if a small disturbance (a perturbation) will die out or, in the case of an unstable system, will grow to become a periodic form. Recurring, geometrically regular phenomena found in Nature can often be explained by such an instability mechanism. The approach used was to investigate if the regularity and geometry of sorted patterned ground could be explained by an instability in the active layer above permafrost (or in the layer of diurnal freeze-thaw action above seasonally frozen ground). Specifically, the onset of Rayleigh convection cells in the porous medium of the active layer was determined. Rayleigh convection refers to fluid convection due to unstable density stratification as a result of thermal gradients. Dense fluid overlying less dense fluid will, under the proper conditions, form convection cells, thus lowering the system free energy. This problem was first investigated by John William Strutt, Lord Rayleigh (Strutt, 1916).

Rayleigh convection has been advanced as an explanation for sorted patterned ground before. Nordenskjöld (1909) suggested that sorted polygons are a result of convection currents in the ground due to the temperature difference between the surface of the frost table and the surface of the thawed ground. Low (1925) and Gripp (1927, 1929) proposed that currents capable of lifting stones occurred due to the density inversion of water between $273 \mathrm{~K}$ and $277 \mathrm{~K}$. However, Elton (1927) showed that the flow caused by this density difference is too small to carry stones against gravity. Gripp and Simon (1934 cited by Washburn, 1956, p. 853) demonstrated the formation of convection cells in a suspension of fines in water with a variation in temperature from $273 \mathrm{~K}$ at the bottom to $277 \mathrm{~K}$ at the top. However, since this suspension of fines did not constitute a porous medium, Gripp and Simon did not reproduce field conditions. It should be noted that the model developed in this paper, while involving Rayleigh convection, is completely different from the convection models discussed above.

The scope of this paper is as follows. First, a hypothesis for the regularity of sorted patterned ground based on the Rayleigh convection model is advanced. It should be emphasized that this model does not attempt to explain the entire formation of sorted patterned ground; rather, it provides a mechanism for the occurrence of regularity in the active layer. Second, a theoretical study of the onset of Rayleigh convection cells in the active layer is presented. The criteria for the formation of these convection cells are determined using a linear stability analysis. This section can be omitted with no loss of continuity for the reader interested only in the physics of this hypothesis. Next, a field program involving width and depth measurements of sorted polygons is presented. These data are compared with the prediction of the Rayleigh convection-cell model. In addition, data from laboratory experiments on Rayleigh convection in porous media are also compared with the predictions of the model. Finally, additional qualitative field observations are presented in support of the Rayleigh convection model for the regularity of sorted patterned ground. Many anomalies associated with sorted patterned ground are explained by the hypothesis developed here.

\section{RAYLEIGH CONVECTION MODEL FOR PATTERNED GROUND REGULARITY}

The process to be described here is hypothesized to apply to a permafrost environment with an active layer which thaws and refreezes seasonally. The diurnal-type sorted polygons developed without a permanently frozen substrate will be discussed in a later section.

Consider the water-saturated active layer depicted schematically in Figure 3. The ice-liquid interface between the frozen and unfrozen ground is at $273 \mathrm{~K}$. For modeling purposes, it is 


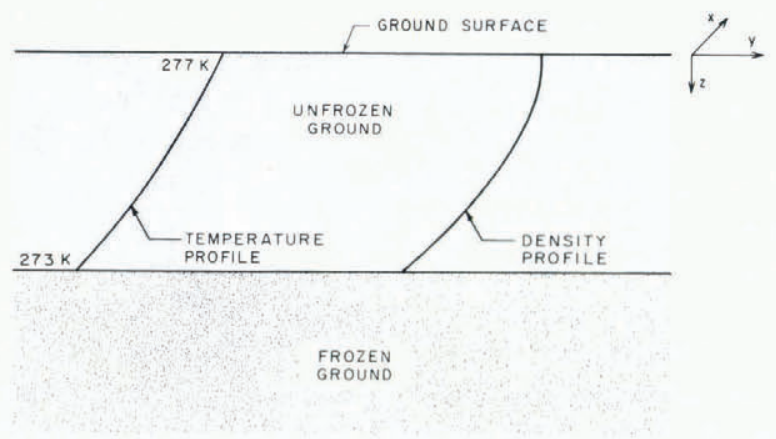

Fig. 3. Schematic of saturated porous media used to model the active layer. The $277 \mathrm{~K}$ isotherm is shown at the surface for convenience.

assumed that the ground surface is at or near $277 \mathrm{~K}$ [this situation often occurs naturally (e.g. Ives, 1973; Washburn, [ $\left.{ }^{c} 1979\right]$, p. 59); situations where the surface temperature is different from $277 \mathrm{~K}$ are easily incorporated into the model and are discussed in the theory section]. It is well known that in this temperature range, the density of water increases with temperature. The density profile of the water between $273 \mathrm{~K}$ and $277 \mathrm{~K}$ is also shown in Figure 3.

Since the density of the water near the surface of the active layer is greater than that near the ice-liquid interface (see Fig. 3), the system is potentially unstable. If the proper conditions exist, the dense upper water will tend to sink while the less dense lower water will tend to rise. Both effects obviously cannot happen at once: at any point the fluid can be ascending or descending, but it cannot move in both directions at the same place and time. This impasse is avoided by the spontaneous division of the system into a pattern of convection cells in each of which the fluid circulates in a closed orbit. The amazing thing about this convection system is that the flow pattern is not one large convection cell; rather, as was discovered by Benard (1900), the system forms many small convection cells whose size and shape can be predicted theoretically.

Lord Rayleigh (Strutt, 1916) showed that convection cells do not form in every fluid layer with an inverse density stratification. The onset of convection cells is controlled by opposing forces. The density gradient and corresponding buoyancy forces must be large enough to force the fluid to circulate. The viscous drag, which in an active layer is a function of the viscosity of the water and the permeability of the soil, must be small enough not to damp out the circulation pattern. This criterion is commonly expressed in terms of a critical value of a dimensionless parameter called the Rayleigh number $(R a)$. The Rayleigh number is a measure of the ratio of the buoyancy force divided by the product of the viscous drag and the rate of heat conduction. Any parameter which makes the Rayleigh number large contributes to the formation of Rayleigh convection cells. The Rayleigh number is defined by

$$
(R a) \equiv \frac{\rho_{\mathrm{c}}^{2} C_{p} \beta \Delta T k g L}{\lambda_{\mathrm{s}} \mu}
$$

where $\rho_{\mathrm{c}}$ is the density of the fluid at its reference temperature (water at $273 \mathrm{~K}$ ), $C_{p}$ is the heat capacity at constant pressure, $\beta$ is the thermal expansion coefficient, $\Delta T$ is the temperature difference imposed across the depth $L, k$ is the permeability, $g$ is the gravitational acceleration, $\lambda_{\mathrm{s}}$ is the thermal conductivity, and $\mu$ is the shear viscosity. The critical Rayleigh number above 
which the onset of convection cells will occur will be determined for the active layer in the theory section to follow.

With the aid of these Rayleigh instability arguments, a sequence of events is now proposed for the formation of sorted polygons. First, it is assumed that for the active layer depicted in Figure 3, the permeability $k$ of the soil is initially too low for the density inversion to result in Rayleigh convection cells; that is, the $k$ which appears in the numerator of Equation (1) is so small that the Rayleigh number is below its critical value. The thickness of the active layer is often nearly the same each year because the permafrost often melts nearly to the same depth each summer (Ives, 1973; Washburn, [ $\left.{ }^{\mathrm{c}} 1979\right]$, p. 59). Frost heave causes vertical (the primary degree of freedom for movement) expansion of the active layer. On thawing, it does not settle to its original density; that is, it stays slightly lofted. Corte (1962) has shown experimentally that up to a $10 \%$ increase in volume of the active layer can result from as few as ten freeze-thaw cycles. Application of the Blake-Kozeny equation (Bird and others, 1960, p. 199) indicates that a single $10 \%$ volume increase can result in an increase in permeability of nearly $70 \%$. After many such freeze-thaw cycles, the active layer will have lofted enough to reach a permeability which allows the critical Rayleigh number to be reached. If the $273 \mathrm{~K}$ to $277 \mathrm{~K}$ temperature difference is present across the active layer, all properties appearing in Equation (1) will be nearly constant except the permeability $k$ and the depth $L$.

Attaining the critical Rayleigh number then is first possible when the variable parameters in the Rayleigh number reach their extreme values; that is $k$ is large enough to achieve the onset of convection when $L$ is at its maximum (deepest annual thaw). Note here that the Rayleigh number is largest when the surface temperature is at or near $277 \mathrm{~K}$. This implies that convection cells will be initiated at that time of the year when the surface temperature is about $277 \mathrm{~K}$.

Earlier models which attempted to explain the regularity of patterned ground by Rayleigh convection were based on the contention that these weak circulatory currents could cause direct movement of the larger stones which form the borders of sorted polygons. The model developed in this paper is not based on any argument that Rayleigh convection cells can move stones directly to effect a sorting process. Instead, this model contends that Rayleigh convection determines the regularity indirectly through its influence on the shape of the ice front which underlies the water-saturated porous medium.

The influence of Rayleigh convection on the shape of the underlying ice front was ignored in earlier models for patterned-ground regularity which were based on Rayleigh convection. The Rayleigh convection cells determine the shape of the underlying ice front because they induce uneven heat transfer to this front. In regions of downflow, the transport of warmer water from the upper layer to the ice front will cause increased melting; conversely, in regions of upflow, the transport of colder water upward will retard melting. Figure 4 shows a schematic diagram of the two-dimensional cross-section of the resulting undulatory ice front. Note the ice peaks under the upflow regions and the ice troughs under the downflow regions. It can be proven that the threedimensional configuration of the Rayleigh convection cells will be hexagonal as shown in Figure $5 \mathrm{a}$ and $\mathrm{b}$. It is not known, however, whether there will be upflow along the cell axis as in Figure $5 \mathrm{a}$ or upflow along the cell border as in Figure 5b. In order to predict the flow configuration of the water-saturated active layer studied here, it is necessary to perform a non-linear stability analysis. The results from such an analysis would then have to be corroborated with laboratory experiments.

As explained above, the critical conditions for Rayleigh convection will first be attained when the maximum temperature driving force $\Delta T=4 \mathrm{~K}$ occurs over the maximum possible depth, that 


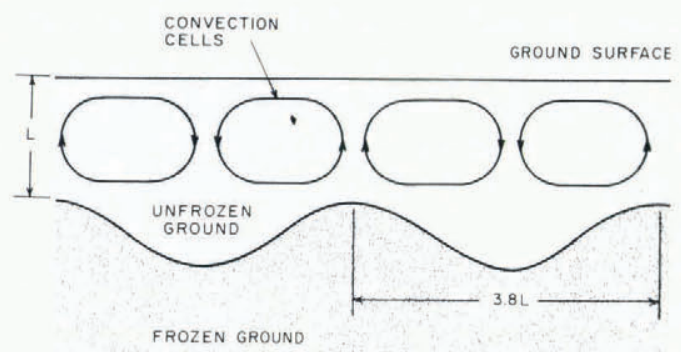

Fig. 4. Two-dimensional cross-section of hexagonal Rayleigh convection cells in the active layer. Note the resulting uneven melting of the permafrost front.

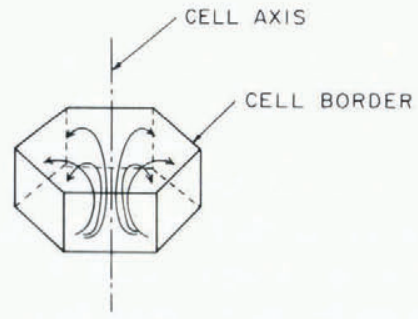

(a)

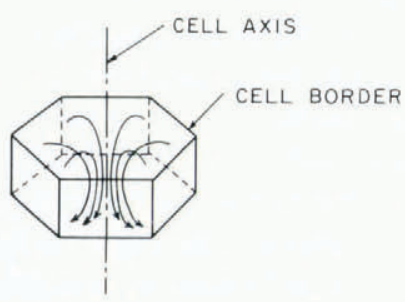

(b)

Fig. 5. Schematic of the two possible hexagonal convection cell configurations: flow up in the center (a) and up in the border (b).

is, the depth of the maximum seasonal thawing. For the conditions appropriate to most patternedground sites studied here, the theoretical analysis in the next section shows that the critical wavelength $W=3.81 \mathrm{~L}$ at the inception of Rayleigh convection. This theoretical result implies that the undulatory ice front will have ice peaks which are 3.81 active layer depths apart as shown in Figure 4. The presence of this undulatory ice front then influences any sorting processes which are slowly occurring in time such that the sorting mirrors the pattern of the underlying ice front. This can occur by any one or a combination of well-established sorting mechanisms such as cryostatic pressure, differential frost heave, and primary frost sorting. It is not the subject of this paper to determine which mechanism or combination of mechanisms causes the sorting process to mirror the patterned ice front. Indeed it is not possible to infer from the type of field data taken in this study which mechanism caused the sorting. However, it is possible to determine if the alleged cause for the regularity of the patterned ground is in fact the undulatory ice front caused by Rayleigh convection. If this new model for explaining the regularity of patterned ground is correct, then the ratio of the polygon width to depth-of-sorting should be equal to 3.81 since the depth-of-sorting should be nearly equal to the depth of the active layer.

This prediction for the width to depth-of-sorting ratio for sorted polygons is a principal result of the theoretical analysis to be discussed next. A large part of the field program was designed to corroborate this prediction with measurements of sorted polygons. The results of this field program will be presented in the field-studies section. The theoretical development in the next section will present the linear stability analysis on the active layer system which results in the prediction for the critical wave-number which was used to establish the ratio of width to depthof-sorting for patterned ground. The reader who is not interested in the mathematical details underlying the model presented here can proceed directly to the field-studies section. 


\section{THEORETICAL DEVELOPMENT}

This section presents the theoretical analysis of Rayleigh convection in an active layer incorporating the presence of an underlying compliant ice front. An explanation of convective instability is provided in the first part of this section, and the system of interest in these modeling efforts is described. The linear stability analysis of this system is subsequently presented and the predictions of the model for Rayleigh convection in the active layer are summarized. Although this analysis is straightforward, it is quite lengthy and hence can only be outlined here. The interested reader desiring more details of this development is referred to Ray (unpublished).

Consider a horizontal layer of a porous medium saturated with a fluid which is unstably stratified. The temperature profile in this layer is such that the density of the fluid at the lower boundary is less than that of the fluid next to the upper boundary. Small-scale inhomogeneities in the porous medium or some other source of small disturbances are assumed to provide a perturbation. This perturbation moves a packet of fluid vertically from its rest state. If the system is unstable, the packet will keep moving and convection cells will form. These convection cells have a lower energy state than the stationary, unstably stratified layer of fluid. A linear stability analysis (discussed below) will establish a criterion involving the characteristic parameters of the system for determining if such a perturbation will grow. This analysis will also give the initially preferred size of the disturbance developed from the perturbation. This is often a good indication of the fully developed convection cell size (Miller, 1978, p. 234).

The active layer during melting is represented schematically in Figure 3. The unfrozen portion is water-saturated earth and can thus be modeled as a saturated porous medium. The temperature profile and the density profile of the water between $273 \mathrm{~K}$ and $277 \mathrm{~K}$ are also shown in Figure 3. The density of water at $277 \mathrm{~K}$ is only $0.0132 \%$ greater than at $273 \mathrm{~K}$. It is well known, however, that this very small density driving force will result in Rayleigh convection cells under the right conditions. The system depicted in Figure 3 is therefore potentially unstable. The surface temperature could be greater than $277 \mathrm{~K}$, in which case the density inversion would occur across only part of the thawed layer. The effects of this and the opposite case of a surface temperature less than $277 \mathrm{~K}$ are to change the depth $L$ over which the unstable stratification occurs. The purpose of the following linear stability analysis is to establish the conditions under which Rayleigh convection will occur in the saturated layer and to predict the size and shape of the convection cells.

Before the linear stability analysis of the system can be carried out, the basic-state temperature profile (i.e. without convection) present in the saturated porous layer must be derived. This profile for the dimensional temperature $T^{\star}$ for the case of negligible heat conduction in the underlying ice is given by Carslaw and Jaeger (1959, p. 282-96);

$$
T^{\star}=T_{\text {surf }}+\left(T_{\text {int }}-T_{\text {surf }}\right) \frac{\operatorname{erf}\left(z^{\star} \lambda / L\right)}{\operatorname{erf}(\lambda)}
$$

where $z^{\star}$ is the dimensional spatial coordinate measured from the ground surface. Equation (2) satisfies the boundary conditions corresponding to a specified temperature at the upper boundary $T_{\text {surf }}$ and the phase-transition temperature $T_{\text {int }}$ at the lower boundary. The dimensionless quantity $\lambda$ is related to the velocity of the phase-transition front. An energy balance at this ice-liquid interface yields an implicit equation for $\lambda$,

$$
\frac{T_{\text {int }}-T_{\text {surf }}}{\operatorname{erf}(\lambda)} \exp \left(-\lambda^{2}\right)=\frac{H \varepsilon \lambda \pi^{1 / 2}}{C_{p}}
$$


in which $\varepsilon$ is the porosity and $H$ is the heat of fusion. Since $\lambda$ is small for the physical parameters describing the active layer, Equation (2) can be represented by the first term of its Taylor-series expansion about $\lambda=0$. This yields an approximation for the basic-state temperature profile involving only the parameter $\lambda^{2}$. Non-dimensionalizing this expansion yields a linear basic-state temperature profile

$$
T=\frac{\left(T^{\star}-T_{\text {int }}\right)}{\left(T_{\text {surf }}-T_{\text {int }}\right)}=1-z
$$

where $z=z^{\star} / L$.

The analysis presented here is the mathematical equivalent of perturbing the fluid packet and determining whether the disturbance will grow into convection cells or decay to its former state. This is done by describing the system with governing equations, then non-dimensionalizing, perturbing, and combining these equations into a fourth-order partial-differential equation. This equation is then solved and the appropriate boundary conditions applied to yield an algebraic equation which indicates the conditions under which the system is unstable and, if so, the initial size of the disturbances or convection cells.

The equation governing flow through porous media is Darcy's Law (Darcy, 1856, in Cheng, 1978):

$$
\boldsymbol{w}^{\star}=-\frac{k}{\mu}\left(\nabla P^{\star}-\rho^{\star} \boldsymbol{g}\right)
$$

where $w^{\star}$ is the dimensional fluid velocity vector, and $P^{\star}$ is the dimensional pressure. Throughout this development, the symbol $\nabla$ will denote the vector differential operator.

The equation of motion for this system is (Bird and others, 1960; p. 79):

$$
\rho^{\star} \frac{\mathrm{D}^{\star} \boldsymbol{w}}{\mathrm{D} t^{\star}}=-\nabla^{\star} P^{\star}-\nabla^{\star} \cdot \tau^{\star}+\rho^{\star} \boldsymbol{g}
$$

where the viscous stress tensor $\tau^{\star}$ is given by

$$
\nabla^{\star} \cdot \boldsymbol{\tau}^{\star}=\frac{\boldsymbol{w}^{\star} \mu}{k} .
$$

The thermal energy equation can be written as (Bird and others, 1960, p. 316):

$$
\rho^{\star} C_{p} \frac{\mathrm{D}^{\star} T^{\star}}{\mathrm{D} t^{\star}}=\lambda_{\mathrm{s}} \nabla^{\star 2} T^{\star} .
$$

The equation of continuity is (Bird and others, 1960, p. 75):

$$
\frac{\mathrm{D}^{\star} \rho^{\star}}{\mathrm{D} t^{\star}}=-\rho^{\star}\left(\nabla^{\star} \cdot \boldsymbol{w}^{\star}\right)
$$

Finally, the equation of state used in this analysis describes the density behavior of water between $273 \mathrm{~K}$ and $277 \mathrm{~K}$ and is given by:

$$
\rho^{\star}=\rho_{\mathrm{c}}\left(1+\beta T^{\star}\right)
$$

Note that the density increases with temperature for positive $\beta$. 
The dependent variables (temperature, velocity, and pressure) are now perturbed about their quiescent values. These perturbation variables denoted by the superscript primes (') are then substituted in Equations (5) through (10) which are then linearized in the perturbed quantities. Subtracting the basic-state equations from these linearized perturbed equations, nondimensionalizing, and combining yields a fourth-order partial differential equation in the perturbed temperature $T^{\prime}$ given by

$$
\left[\frac{w_{\mathrm{s}} \lambda_{\mathrm{s}} \Delta T}{L^{2} \varepsilon H \rho_{\mathrm{c}} g} \frac{\partial}{\partial t}+\frac{\mu w_{\mathrm{s}}}{k g \rho_{\mathrm{c}}}\right]\left[\frac{\lambda_{\mathrm{s}}}{\varepsilon L H w_{\mathrm{s}} \rho_{\mathrm{c}} \beta} \frac{\partial}{\partial t}-\frac{\lambda_{\mathrm{s}}}{w_{\mathrm{s}} \rho_{\mathrm{c}} C_{p} L \beta \Delta T} \nabla^{2}\right] \nabla^{2} T^{\prime}=\nabla_{1}^{2} T^{\prime}
$$

in which the temperature and spatial coordinates are non-dimensionalized as described earlier, $w_{\mathrm{s}}$ is an unspecified velocity scale factor, and the dimensionless time is given by $t=t^{\star} \lambda_{\mathrm{s}} \Delta T /\left(L^{2} \varepsilon H \rho_{\mathrm{c}}\right)$. The symbol $\nabla_{1}^{2}$ denotes the two-dimensional Laplacian operator given by

$$
\nabla_{1}^{2} \equiv \frac{\partial^{2}}{\partial x^{2}}+\frac{\partial^{2}}{\partial y^{2}} \text {. }
$$

The solution to Equation (11) is found to be

$$
T^{\prime}=\mathrm{e}^{n t} \sin (l x) \sin (m y)\left(A_{1} \mathrm{e}^{r_{1} z}+A_{2} \mathrm{e}^{-r_{1} z}+A_{3} \mathrm{e}^{r_{2} z}+A_{4} \mathrm{e}^{-r_{2} z}\right)
$$

where $n \equiv n^{\star} L^{2} \varepsilon H \rho_{\mathrm{c}} / \lambda_{x} \Delta T$ is the dimensionless growth coefficient. The symbols $l$ and $m$ are dimensionless horizontal wave-numbers in the $x$ - and $y$-directions (see Figure 3 ), respectively, defined by

$$
\begin{aligned}
& l \equiv \frac{2 \pi L}{W_{x}}, \\
& m \equiv \frac{2 \pi L}{W_{y}},
\end{aligned}
$$

in which $W_{x}$ and $W_{y}$ denote the dimensional wavelengths in the $x$ - and $y$-directions, respectively. It is convenient to define a combined dimensionless, horizontal wave-number $a$ as

$$
a^{2}=l^{2}+m^{2} \text {. }
$$

The dimensionless quantities $r_{1}$ and $r_{2}$, appearing in Equation (13) are defined as

$$
r_{1} \equiv\left[\frac{\alpha+2 \xi a^{2}-\left(\alpha^{2}+4 \xi \alpha a^{2}+4 \xi(1-\alpha) a^{2}\right)^{1 / 2}}{2 \xi}\right]^{1 / 2}
$$

and

$$
r_{2} \equiv\left[\frac{\alpha+2 \xi a^{2}+\left(a+4 \xi \alpha a^{2}+4 \xi(1-\alpha) a^{2}\right)^{1 / 2}}{2 \xi}\right]^{1 / 2}
$$

where

$$
\begin{gathered}
\alpha \equiv \frac{C_{p} \Delta T n}{\varepsilon H(R a)}, \\
\xi \equiv \frac{1}{(R a)} .
\end{gathered}
$$


The symbol $(R a)$ denotes the Rayleigh number defined by Equation (1). Its appropriate minimum value is the criterion for the onset of convection in the active layer, which will be discussed further in a later section. The four quantities, $A_{1}, A_{2}, A_{3}$, and $A_{4}$ in Equation (13) are the four undetermined integration constants. Therefore, four boundary conditions are required to specify the problem completely.

The upper boundary of the unstably stratified layer is a free surface in that it is free to deform in response to the dynamics of the flow process. This free surface is defined by the condition of zero flow velocity normal to this surface. The appropriate boundary condition for the linear stability problem can be shown to be

$$
w^{\prime}=0 \quad \text { at } z=0 .
$$

The same boundary condition can be shown to apply at the "interface" between a stably stratified layer and an unstably stratified lower layer. This is a direct consequence of the linearizations employed in this linear stability theory solution. Equation (21) can be expressed in terms of the perturbed temperature as follows:

$$
\nabla^{2} T^{\prime}-\left(\frac{C_{p} \Delta T}{\varepsilon H}\right) \frac{\partial T^{\prime}}{\partial t}=0 \quad \text { at } z=0 .
$$

The boundary condition corresponding to a specified upper temperature is given in terms of perturbed temperature by

$$
T^{\prime}=0 \quad \text { at } z=0 .
$$

The lower boundary condition corresponding to an impermeable, compliant, phase-transition front is given in dimensionless form by

$$
w^{\prime}=0 \quad \text { at } z=1 .
$$

Equation (24) can be put in terms of $T^{\prime}$ in a manner similar to that used for Equation (21) to yield

$$
\nabla^{2} T^{\prime}-\left(\frac{C_{p} \Delta T}{\varepsilon H}\right) \frac{\partial T^{\prime}}{\partial t}=0 \quad \text { at } z=1 .
$$

The lower boundary condition describing the moving ice-liquid interface is given, in dimensionless form, by

$$
\frac{\mathrm{d} \eta}{\mathrm{d} t}=-\frac{\partial T^{\prime}}{\partial z}+\frac{\partial^{2} \bar{T}}{\partial z^{2}} \eta \quad \text { at } z=1 .
$$

The ice-liquid interace is allowed to melt unevenly in this analysis, which requires a new variable $\eta(x, y)$ to describe the undulation. The introduction of this extra degree of freedom requires an additional lower boundary condition. This third lower boundary condition comes from the fact that the ice-water interface is at a constant temperature. This condition can be written as

$$
T^{\prime}+\frac{\partial \bar{T}}{\partial z} \eta=0 \quad \text { at } z=1 .
$$

Substituting the basic-state temperature profile given by Equation (4) into Equations (27) and 
(28) to eliminate $\eta$ and then combining these equations yields a lower boundary condition independent of $\eta$ given by

$$
\frac{\partial T^{\prime}}{\partial z}+\frac{\partial T^{\prime}}{\partial t}=0 \quad \text { at } z=1 .
$$

The solution given by Equation (13) is then substituted into the four boundary conditions, Equations (22), (23), (25) and (28). Since the boundary conditions are homogeneous, the determinant of the coefficients of the integration constants $A_{1}, A_{2}, A_{3}$, and $A_{4}$ must be equal to zero in order to obtain a nontrivial solution. Evaluating this determinant yields, after considerable algebraic manipulation,

$$
\begin{array}{r}
{\left[\left(a^{2}+r_{1}^{\prime 2}+W_{T} n\right)^{2}+\left(a^{2}+r_{1}^{\prime 2}+W_{T} n\right)\left(-a^{2}+r_{2}^{2}-W_{T} n\right)\right] r_{2} \sin r_{1}^{\prime} \cosh r_{2}+} \\
+\left[\left(-a^{2}+r_{2}^{2}+W_{T} n\right)^{2}-\left(-a^{2}+r_{2}^{2}-W_{T} n\right)\left(-a^{2}+r_{1}^{\prime 2}-W_{T} n\right)\right] r_{1}^{\prime} \cos r_{1}^{\prime} \sinh r_{2}+ \\
+\left[\left(a^{2}+r_{1}^{\prime 2}+W_{T} n\right)^{2}+\left(-a^{2}+r_{2}^{2}-W_{T} n\right)^{2}\right] n \sin r_{1}^{\prime} \sinh r_{2}+2\left(a^{2}+r_{1}^{\prime 2}+W_{T} n\right) \times \\
\times\left(-a^{2}+r_{2}^{2}-W_{T} n\right) n \sin r_{1}^{\prime} \sinh r_{2}=0
\end{array}
$$

where

$$
W_{T}=\frac{C_{p} \Delta T}{\varepsilon H}
$$

and

$$
r_{1}^{\prime}=\mathrm{i} r_{1} .
$$

Equation (29) constitutes a relationship between the parameters of the problem which include the physical properties, prescribed temperatures at the boundaries, active-layer depth, wavenumber $a$, and growth coefficient $n$. For a specified set of physical properties and prescribed boundary conditions, there is a unique growth coefficient $n$ determined by Equation (29) for each wave-number. Only wave-numbers with positive growth coefficients are unstable modes which can be observed. At Rayleigh numbers less than the critical Rayleigh number, $n$ is negative for all wave-numbers. At the critical wave-number, $n$ is equal to zero for the critical wave-number and is negative for all other wave-numbers. At slightly higher Rayleigh numbers, $n$ is positive for a small band of wave-numbers around the critical wave-number. For this reason, the convection cells which are observed when the system first exceeds the critical Rayleigh number have a size characterized by the critical wave-number.

The predictions of Equation (29) are shown in Figure 6 which plots the dimensionless wavenumber $a$ versus the Rayleigh number $(R a)$. The shaded area corresponds to those wavenumbers which have a positive growth coefficient $n$ and hence could grow to become convection cells of finite size. This region of unstable wave-numbers is bounded by the locus of those wavenumbers for which $n=0$, which is referred to as the neutral stability curve. The critical Rayleigh number here is seen to be 27.1 and corresponds to a critical wave-number of 2.33. At any Rayleigh number above the critical Rayleigh number, there is a unique wave-number having the largest positive growth coefficient which is referred to as the most highly amplified wave. The locus of these most highly amplified wave-numbers is also shown in Figure 6.

It must be stressed here that the most highly amplified wave for each Rayleigh number only describes the perturbation which grows most rapidly initially. Strictly speaking, linear stability 


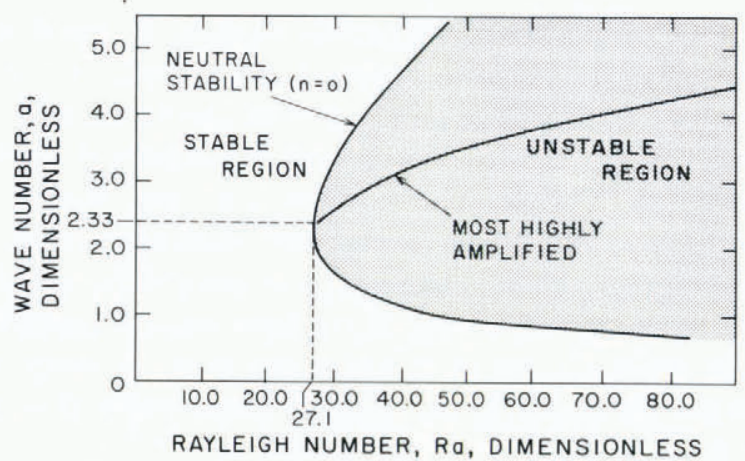

Fig. 6. Wave-number versus Rayleigh number for the boundary conditions corresponding to a free upper surface maintained at constant temperature. Critical Rayleigh number is 27.1 , critical wave-number is 2.33.

theory cannot describe cell development and size beyond the initial perturbation. However, it is often found that the initially most highly amplified wave describes the wave-number of fully developed convection cells at a given Rayleigh number. Furthermore, at Rayleigh numbers only slightly above critical, the critical wave-number persists (Velarde and Normand, 1980; Combarnous and Bories, 1975), presumably because the critical wave-number has had time to become well developed enough to dominate disturbances of other wave-numbers.

The hypothesis advanced here for the regularity of sorted patterned ground argues that a prospective patterned-ground site is brought up to the critical condition at which Rayleigh convection is possible, by a gradual increase in the Rayleigh number due to successive freeze-thaw cycles. Once the critical Rayleigh number is reached, the initial convection cells which develop will have a size characterized by the critical wave-number. The underlying ice front will deform in response to the uneven heat transfer due to the free convection cells. At the same time, the convection cells effect minute changes in the porous medium due to silt flow, compaction, and rarefaction of the soil, and other effects which favor re-establishing the convection cells in the same place during subsequent thaw cycles. Hence, the convection cells which are initially generated in the porous medium at critical conditions impart a geometric character to the medium which persists through subsequent freeze-thaw cycles. Furthermore, this impressed geometric character should be manifest in the patterned ground arising from sorting processes. That is, sorted polygons should have a ratio of width to depth-of-sorting determined by the critical wave-number predicted by Equation (29), $a=2.33$. For a laterally isotropic porous medium, we expect that $W_{x}=W_{y}$ in Equations (14) and (15); hence, Equation (16) implies that the width to depth-of-sorting ratio corresponding to the critical wave-number is given by

$$
a=2.33=2 \pi \sqrt{2} L / W \text {. }
$$

Hence,

$$
W / L=3.81 \text {. }
$$

This establishes one of the principal results of this analysis which can be tested against field measurements of sorted polygons. An important point to note here is that this prediction of critical wave-number (Equation (32)) or ratio of width to depth of sorting (Equation (33)) is 
independent of the physical properties of the porous medium. In order to test its validity, one need only measure the polygon width to depth-of-sorting ratio for patterned-ground sites. Further predictions about the nature of patterned ground can be made with the use of Rayleigh convection theory. Palm (1960) showed that Rayleigh convection cells in a free-fluid layer approach a hexagonal form. Furthermore, Combarnous and Bories (1975) demonstrated experimentally that Rayleigh cells in porous media are indeed hexagonal. These theoretical and experimental results suggest that the preferred shape of patterned ground formed as a result of Rayleigh convection will be hexagonal in a flat active layer which is laterally isotropic.

Finally, this analysis suggests that these hexagonal patterns observed on flat terrain will transform to parallel stripes on sloped terrain. Parallel stripes imply that either $W_{x}$ or $W_{y}=0$ in Equations (14) or (15); hence, Equation (16) implies that

$$
2.33=2 \pi L / W
$$

or that

$$
W / L=2.70 \text {. }
$$

In the next section these predictions will be compared with field observations of both relict and active patterned ground.

\section{FIELD STUdies}

Field observations were intended to test the hypothesis that the regularity of sorted patterned ground corresponds to that predicted for Rayleigh convection cells. This would suggest that Rayleigh convection in the active layer is responsible for the observed regularity of sorted patterned ground. If Rayleigh convection is involved in sorted-polygon inception, it would have occurred long ago in relict sites that are now polygonally patterned; however, sites about to form sorted polygons are very difficult to identify. For this reason, the field studies presented below focused on measurements of existing sorted polygons as a test of the Rayleigh convection hypothesis.

Since the Rayleigh convection hypothesis predicts a convection cell width-to-depth ratio of 3.81 , and sorting to the depth of cell development is assumed, width and depth measurements of sorted polygons were needed. Although many investigators have noticed the relationship between the width of sorted polygons and the depth-of-sorting of the rocky borders, few depth and width data exist in the literature. The field program, then, focused on obtaining accurate depth and width data over a range of sorted polygon sizes.

Once a site was chosen for study, a well-formed sorted polygon was chosen for trenching. Well-defined borders, the apparent absence of large boulders, and adjacent, well-formed polygons were the criteria employed in deciding where to excavate. Trenching affords one important advantage over just digging to the bottom of the rock border in that it permits observation of the cross-sectional shape of the polygon border.

The depth of sorting was measured from a reference level, provided by a tape stretched from center to center of a polygon, down to the point determined as the bottom of the border (see Fig. 7). In other words, the reference level was the undisturbed ground level regardless of how high the rocky border was above the ground. Often, as in Figure 7, the location of the bottom of the rocky border was visually obvious. In other cases, the depth-of-sorting or the orientation of the 


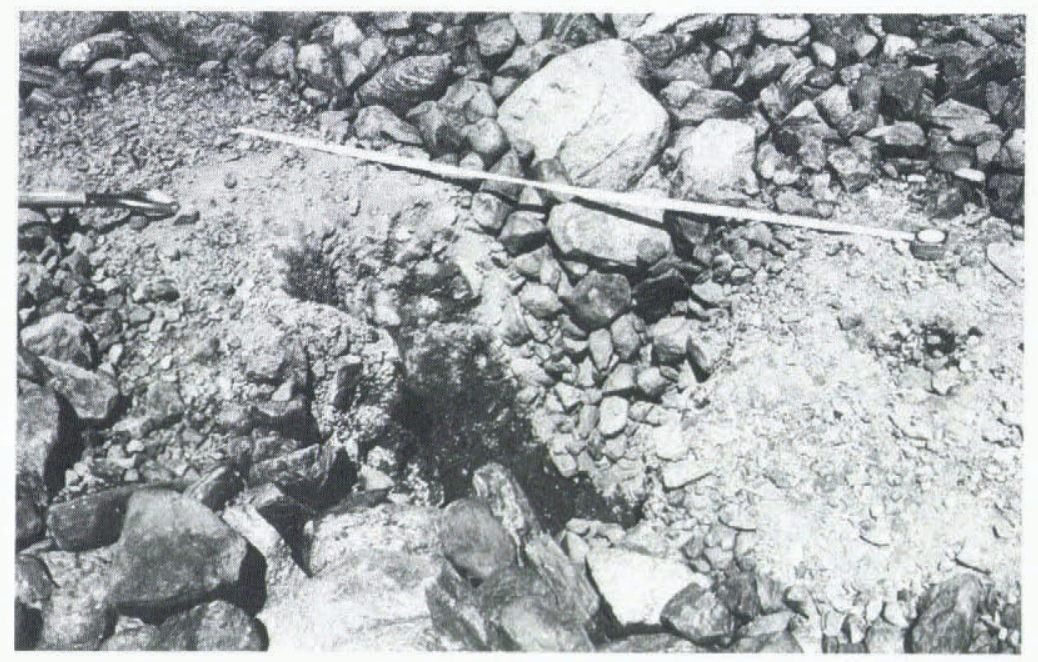

Fig. 7. Typical trench across border of sorted polygons. Stretched tape shows undisturbed ground level.

stones was used to determine the bottom of a rocky border. Vertically oriented stones were considered part of the border. A preponderance of horizontally oriented stones, on the other hand, was assumed to lie below the level of freeze-thaw action at the time of polygon formation. Therefore, the depth at which stones became horizontally oriented was considered the depth of the sorted rocky border. The widths from polygon centers to the center of the rocky borders of several adjacent sorted polygons were measured to obtain an average width.

Table I summarizes the data used to test the model advanced here for the regularity of patterned ground. The location and elevation of each site as well as the polygon width and depth, and the investigator are included in Table I. The polygons were for the most part relict, although a few small, active, sorted polygons were studied. Relatively few sites exhibited well-developed sorted stripes, hence the predictions of Equations (34) or (35) could not be tested.

The preceding section established that the critical wave-number at the inception of Rayleigh convection is 2.33 , which corresponds to a cell width to depth ratio of 3.81 . The hypothesis for patterned ground regularity to be tested here argues that the undulatory ice front created by the Rayleigh convection cells transmits its pattern through the sorting process to the developing patterned ground. The hypothesis implies that sorted patterned ground whose regularity is due to this mechanism should have a ratio of width to depth-of-sorting of 3.81 , or equivalently, a dimensionless wave-number $a=2 \pi \sqrt{2} L / W=2.33$. This prediction is tested in Figure 8 which plots the polygon width $W$ versus the depth-of-sorting $L$ for the 18 field study data given in Table I. A linear regression on these data gives a slope of 3.57 and an intercept of $0.04 \mathrm{~m}$ with a correlation coefficient of 0.982 . Perfect agreement with the theory, of course, would imply a slope of 3.81 , an intercept of 0 and a correlation coefficient of unity. It should be mentioned here that while there are a number of approximations in the theory developed here, it is believed the cause of most of the deviations from the theoretical line in Figure 8 arise from the irregularity inherent in geological phenomena.

Note that Figure 8 includes field data for both seasonal polygons (shown by the open data points) and active diurnal sorted polygons (shown by the dark data points). Hence, this model 
TABLE I. FIELD STUdy DATA FOR SORTED POLYGONS

\begin{tabular}{|c|c|c|c|c|c|}
\hline Site location & USGS quadrangle & $\begin{array}{l}\text { Width } \\
(\mathrm{m})\end{array}$ & $\begin{array}{l}\text { Depth } \\
(\mathrm{m})\end{array}$ & $\begin{array}{l}\text { Approx. } \\
\text { elevation } \\
(\mathrm{m})\end{array}$ & Investigator(s) \\
\hline Niwot Ridge & Ward, Colorado & 2.3 & 0.53 & 3500 & Ray \\
\hline Niwot Ridge & Ward, Colorado & 3.8 & 1.00 & 3500 & Ray \\
\hline Caribou Mt. & Ward, Colorado & 1.7 & 0.48 & 3650 & Ray \\
\hline Caribou Mt. & Ward, Colorado & 1.7 & 0.48 & 3650 & Ray \\
\hline Arikaree Glacier & $\begin{array}{l}\text { Monarch Lake, } \\
\text { Colorado }\end{array}$ & $0.86^{*}$ & 0.18 & 3800 & Ray \\
\hline Arikaree Glacier & $\begin{array}{l}\text { Monarch Lake, } \\
\text { Colorado }\end{array}$ & $0.83^{*}$ & 0.16 & 3800 & Ray \\
\hline Albion Saddle & Ward, Colorado & $0.40^{*}$ & 0.10 & 3650 & Ray \\
\hline Albion Saddle & Ward, Colorado & $0.50^{*}$ & 0.13 & 3650 & Ray \\
\hline Albion Saddle & Ward, Colorado & 3.9 & 1.10 & 3650 & Ray \\
\hline $\begin{array}{l}\text { Medicine Bow } \\
\text { Peak }\end{array}$ & $\begin{array}{l}\text { Medicine Bow, } \\
\text { Wyoming }\end{array}$ & 2.3 & 0.70 & 3650 & Ray \\
\hline $\begin{array}{l}\text { Medicine Bow } \\
\text { Peak }\end{array}$ & $\begin{array}{l}\text { Medicine Bow, } \\
\text { Wyoming }\end{array}$ & 2.9 & 0.70 & 3650 & Ray \\
\hline Trail Ridge Road & Trail Ridge & 4.0 & 1.10 & 3660 & Ray \\
\hline Green Lake No. 4 & Ward, Colorado & 2.3 & 0.71 & 3550 & Ray \\
\hline Chief Mountain & $\begin{array}{l}\text { Franks Peak, } \\
\text { Wyoming }\end{array}$ & 2.3 & 0.83 & 3400 & Krantz and Gunn \\
\hline Beartooth Plateau & $\begin{array}{l}\text { Beartooth Butte and } \\
\text { Alpine, Montana }\end{array}$ & $0.20^{*}$ & 0.07 & 3400 & Krantz and Gunn \\
\hline Dana Plateau & $\begin{array}{l}\text { Mono Craters, } \\
\text { California }\end{array}$ & 0.64 & 0.16 & 3500 & Krantz and Gunn \\
\hline Parker Pass Creek & $\begin{array}{c}\text { Mono Craters, } \\
\text { California }\end{array}$ & 0.70 & 0.14 & 3400 & Krantz and Gunn \\
\hline $\begin{array}{l}\text { Macquarie Island, } \\
\text { Australia }\end{array}$ & - & $0.25^{*}$ & 0.08 & 300 & Caine \\
\hline
\end{tabular}

for patterned ground regularity permits explaining the width to depth-of-sorting for both largescale relict as well as small-scale diurnal sorted polygons.

An essential aspect of the hypothesis advanced here for patterned ground regularity is that it arises from free convection occurring near the critical Rayleigh number. Whereas sorted patterned ground of the type considered here has yet to be developed in laboratory experiments, there have been exacting laboratory studies of the inception of Rayleigh convection in porous media. Combarnous and Bories (1975) studied the inception of Rayleigh convection in a porous medium saturated with a "normal" liquid (one whose density increases with temperature) which was heated from below and was overlaid by a thin layer of the liquid. Superficially, this system does not resemble the free convection problem treated in this paper. However, the mathematical description of the Rayleigh stability problem for this system is identical to that of interest here; hence, this laboratory study of Combarnous and Bories should also yield a critical wave-number of 2.33 or equivalently a ratio of cell width to depth 3.81. Figure 9 shows a plot of the dimensionless wave number $a$ versus depth $L$ for both the laboratory data of Combarnous and Bories and the sorted-polygon data of Table I. It is more convenient to compare these laboratory and field measurements on the basis of dimensionless wave-number rather than a width-to-depth plot as in Figure 8 because of the much smaller scale of the laboratory convection cells. Both the 
laboratory and field-test wave-number data show no dependence on the depth, which, of course, agrees with the theoretical prediction. The laboratory data yield an average dimensionless wavenumber of 2.64 whereas the field data give an average of 2.3. This comparison demonstrates then that the field data agree as well or better with the theory as do the data from carefully controlled laboratory studies of free convection.

\section{SORTED PATTERNED GROUND CHARACTERISTICS EXPLAINED BY RAYLEIGH CONVECTION} MODEL

This section discusses sorted patterned ground characteristics in the light of the Rayleigh convection hypothesis.

\section{Constant width-to-depth ratio}

It was noted earlier that the width of sorted patterned ground increases with the depth of the sorted boulders. Figures 8 and 9 demonstrate the constancy of the width-to-depth ratio, which is easily explained by the Rayleigh convection model. The Rayleigh convection cells in the soil should correspond to the critical wave-number of 2.33 since the Rayleigh number will be near its critical value. This sets the width-to-depth ratio of these cells at 3.81 , which is remarkably close to the width-to-depth ratio of 3.57 found from the linear regression analysis of the field data.

\section{Sorted stripes}

Sorted stripes are parallel lines of stone and intervening stripes of finer material usually oriented down-slope parallel to the fall-line. While sorted polygons usually occur on slopes of $0^{\circ}$ to $3^{\circ}$, a smooth transition to sorted stripes often occurs between $3^{\circ}$ and $7^{\circ}$. Combarnous and Bories (1975) and others have observed in laboratory experiments that three-dimensional hexagonal convection cells transform to two-dimensional roll cells oriented down-slope as the porous medium is tilted past some critical angle. Sorted stripes then are formed by essentially the

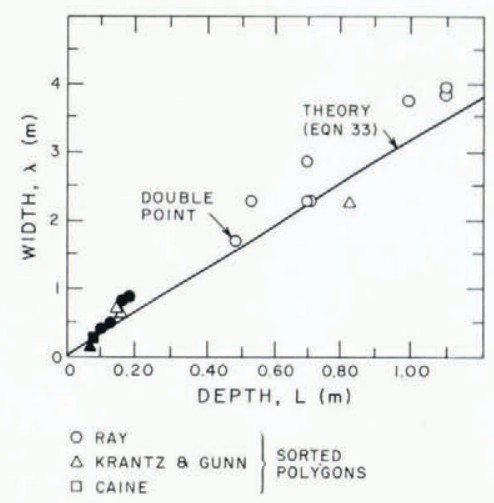

Fig. 8. Characteristic width versus depth of sorting for sorted polygons. The dark points are diurnal sorted polygons.

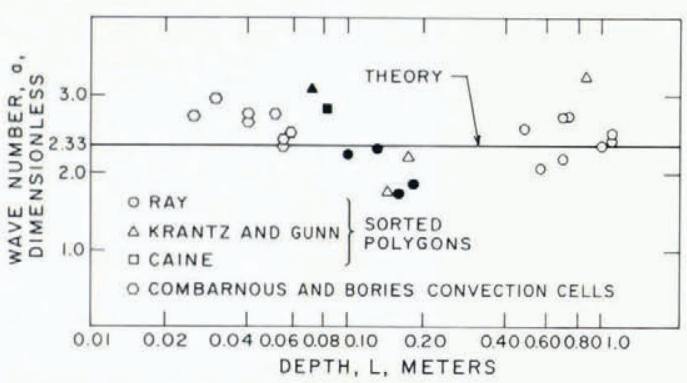

Fig. 9. Wave-number versus depth for sorted polygons and Rayleigh convection cells. Rayleigh convection theory predictions are included. The dark points are diurnal sorted polygons. 
same mechanism as sorted polygons. The two-dimensional roll cells melt the permafrost unevenly, resulting in parallel ice ridges and troughs oriented down-slope. The same sorting mechanism can now occur to form sorted stripes from this undulatory ice front. The anomaly of "stripe hysteresis", i.e. where stone stripes often continue onto flats below the slope (Richmond, 1949), can also be explained by this model. Combarnous (1978) observed in laboratory studies of convection cells that two-dimensional roll cells often persist after the tilted porous medium is suddenly made horizontal. This suggests that in a tilted active layer, the two-dimensional roll cells will persist for some distance after the slope flattens. The observation of Nicholson (1976), that sorted stripes follow subsurface drainage patterns and not necessarily the steepest slope, can also be explained by the convection theory. The two-dimensional roll cells discussed above are flowing down-slope so they would tend to melt the permafrost unevenly following the drainage patterns. Thus, the unfrozen ridges would follow the drainage, not necessarily the surface slope.

\section{Diurnal sorted patterned ground}

Diurnal sorted polygons are those small forms usually less than $0.1 \mathrm{~m}$ in depth which appear to be associated with diurnal freeze-thaw cycles. They fit the same dimensionless wave-number as do the large relict polygons (see Figure 9). Therefore, the same convection-cell model should explain them as describes the large polygons formed in a seasonal active layer over permafrost. In this case only deep seasonal freezing and not necessarily permafrost is present. At the beginning of spring, the ground may be frozen to a depth greater than that which thaws and freezes diurnally. This "diurnal active layer" will refreeze during the night. These diurnal freeze-thaw cycles are often accompanied by diurnal frost-heave cycles (Fahey, 1973). The diurnal sorted polygon in Figure 2 is $15.2 \mathrm{~cm}$ wide. According to the Rayleigh convection model, the top $4 \mathrm{~cm}$ of frozen ground must thaw and refreeze each day. Diurnal freeze-thaw depths of up to $10 \mathrm{~cm}$ have been observed by Fahey (1973) and others. Thus, the same mechanism for regularity can be applied here as was discussed for large-scale sorted polygons. Figure 10 shows a schematic of this process. The permeability of the diurnal active layer rises with the diurnal freeze-thaw cycles until the onset of convection occurs. The convection cells melt the upper surface of the seasonally frozen ground in the same undulatory manner as in the permafrost in

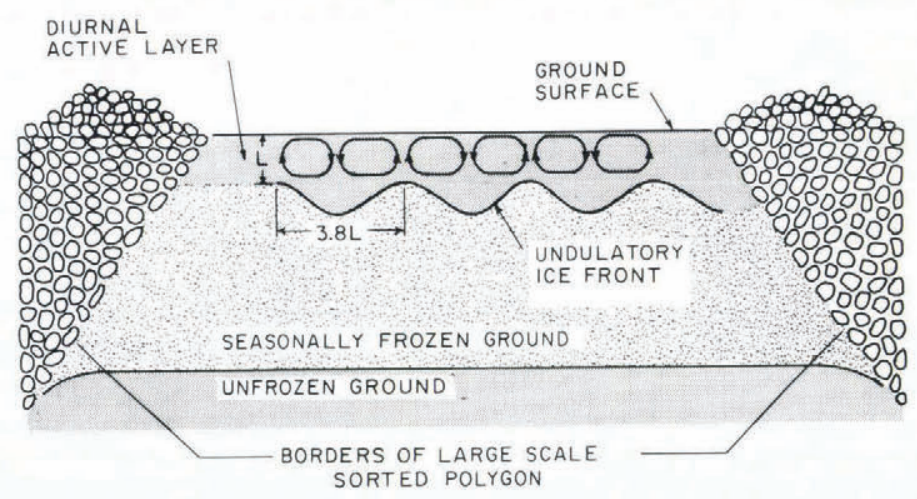

Fig. 10. Schematic of two-dimensional cross-section of Rayleigh convection cells in a diurnal active layer in the center of a large sorted polygon. 
the large-scale situation (seasonally active layer). Sorting mechanisms then use the established undulatory diurnal ice front to form the diurnal patterns (Fig. 2).

\section{Shape of sorted polygons}

Figure 2 is a close-up photograph of a diurnal sorted polygon. This polygon is one group of almost perfect hexagons. Hence, the hexagonal shape of the ice front predicted earlier is in fact observed in Nature. This suggests that the mechanisms which formed the sorted polygon mirror this ice front very closely. It also supports the argument that such diurnal forms are also Rayleigh convection phenomena.

\section{Underwater sorted polygons}

The upper boundary conditions discussed thus far in this paper correspond to an active layer saturated with water up to a level below or at the ground surface. Another possible boundary condition has been observed in field studies only rarely (e.g. Jennings, 1960). This corresponds to polygon formation in sediment beneath standing water. This condition yields a lower critical Rayleigh number than does the usual boundary condition of saturation to the ground surface. The standing-water boundary condition is given by

$$
\frac{\partial w^{\prime}}{\partial z}=0 \quad \text { at } z=0
$$

which replaces Equation (21) as the upper flow boundary condition. Application of Equation (36) yields a critical Rayleigh number of 17.7 instead of the critical Rayleigh number of 27.1 for the free surface case considered earlier in this paper. This would indicate that convection will occur for less extreme conditions (a lower permeability, for example) for the standing water case. Thus, Rayleigh convection in the active layer could occur under a shallow lake or pond which freezes completely in the winter and thaws in the summer. A search for underwater polygons revealed them in the beds of several small ponds in the Snowy Range in Wyoming (Fig. 11) where they have formed under standing water up to about $0.3 \mathrm{~m}$ deep. The critical wave number for the standing-water case is 1.75 , which suggests a width-to-depth ratio of about 5.08 instead of 3.81 . The average width of the Snowy Range polygons is $0.8 \mathrm{~m}$, from which we predict a sorting depth of $0.16 \mathrm{~m}$. This prediction has not yet been tested by excavation.

\section{Conclusions}

The model developed in this paper hypothesizes that Rayleigh convection cells in the active layer cause uneven melting of the ice front, thus forming ice peaks and troughs. The pattern in this ice front is transmitted through established sorting mechanisms to the developing patterned ground. The model predicts a critical cell width-to-depth ratio of 3.81 (for horizontal, initially isotropic active layers) which is independent of the physical properties of the porous medium. Field study data obtained by trenching both large-scale relict polygons and small-scale diurnal polygons agree very well with the theoretical prediction for the ratio of polygon width to depthof-sorting ratio. Furthermore, the model explains several other characteristics of sorted patterned ground including the characteristic hexagonal shape, the transition from sorted polygons to 


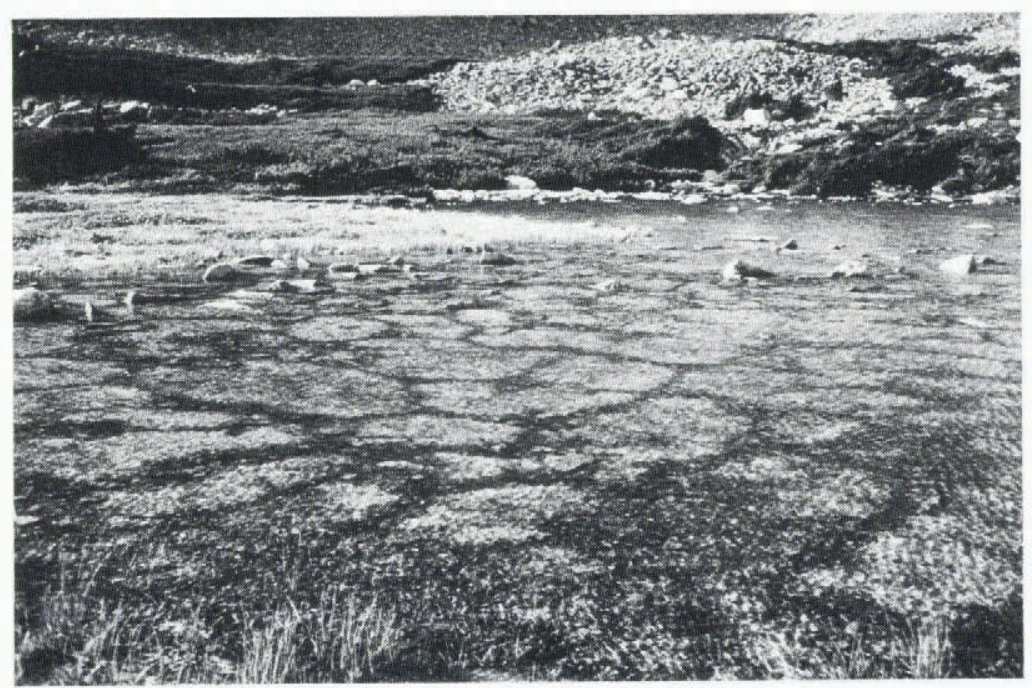

Fig. 11. Underwater sorted polygons, Snowy Range of Wyoming. Polygons are approximately $0.8 \mathrm{~m}$ wide.

sorted stripes with increasing slope, and stripe hysteresis. Finally, the model predicts the occurrence of patterned ground under water with a polygon width to depth-of-sorting ratio of 5.08; however, this prediction has not been tested against field measurements as yet.

\section{ACKNOWLEDGEMENTS}

The authors wish to acknowledge financial support provided for the field studies by the Council for Research and Creative Work of the University of Colorado. The authors also acknowledge Ms Ellen M. Romig and Mr Dennis L. Ehmsen for their assistance in preparing the final manuscript and figures and David Newbold for his help with the field program. A portion of this work was completed while one of the authors (WBK) was a Senior Fulbright Research Scholar at Aachen Technical University in the Federal Republic of Germany. This author gratefully acknowledges the financial support he received through the Fulbright-Hays Program and the Faculty Fellowship Program of the University of Colorado.

MS. received 3 November 1981 and in revised form 9 September 1982

\section{REFERENCES}

Benard, H. 1900. Tourbillons cellulaires dans une nappe liquide. Revue Générale des Sciences Pures et Appliquées, Vol. 11, No. 24, p. 1261-71, 1309-28.

Bird, R. E., and others. 1960. Transport phenomena, by R. E. Bird, W. E. Stewart, and E. N. Lightfoot. New York, John Wiley and Sons, Inc.

Caine, N. 1972. The distribution of sorted patterned ground in the English Lake District. Revue de Geomorphologie Dynamique, $21^{\mathrm{e}}$ An., No. 2, p. 49-56.

Carslaw, H. S., and Jaeger, J. C. 1959. Conduction of heat in solids. Second edition. Oxford, Clarendon Press.

Cheng, P. 1978. Heat transfer in geothermal systems. Advances in Heat Transfer, Vol. 14, p. 4-130. 
Combarnous, M. S. 1978. Natural convection in porous media and geothermal systems. Sixth International Heat Transfer Conference, Toronto, Canada, August 7-11, 1978. Mémoires de confërenciers invités, Vol. 7, p. 65-79.

Combarnous, M. S., and Bories, S. A. 1975. Hydrothermal convection in saturated porous media. Advances in Hydroscience, Vol. 10, p. 231-307.

Corte, A. E. 1962. The frost behavior of soils: laboratory and field data for a new concept. Pt. II. Horizontal sorting. U.S. Cold Regions Research and Engineering Laboratory. Research Report 85, Pt. 2.

Elton, C. S. 1927. The nature and origin of soil polygons in Spitzbergen. Quarterly Journal of the Geological Society of London, Vol. 83, Pt. 1, p. 163-94.

Fahey, B. D. 1973. An analysis of diurnal freeze-thaw and frost heave cycles in the Indian Peaks region of the Colorado Front Range. Arctic and Alpine Research, Vol. 5, No. 3, p. 269-80.

Gripp, K. 1927. Beiträge zue Geologie von Spitzbergen. Abhandlungen aus dem Gebiet der Naturwissenschaften (Hamburg), Bd. 21, Ht. 3-4, p. 1-38.

Gripp, K. 1929. Glaciologische und geologische Ergebnisse der Hamburger Spitzbergen-Expedition 1927. Abhandlungen aus dem Gebiet der Naturwissenschaften (Hamburg), Bd. 22, Ht. 2-4, p. 145-249.

Ives, J. D. 1973. Permafrost and its relationship to other environmental parameters in a midlatitude, high-altitude setting, Front Range, Colorado Rocky Mountains. Permafrost. Second International Conference. 13-28 July 1973, Yakutsk, U.S.S.R. North American contribution, p. 121-25.

Jennings, J. N. 1960. On an unusual occurrence of stone polygons in the French Alps. Biuletyn Peryglacjalny, No. 7 , p. $169-73$.

Low, A. R. 1925. Instability of viscous fluid motion. Nature, Vol. 115, No. 2887, p. 299-300.

Matthews, W. H., and Boyer, R. E. 1976. Dictionary of geological terms. New York, Anchor Press.

Miller, C. A. 1978. Stability of interfaces. Surface and Colloid Science, Vol. 10, No. 3, p. 227-93.

Nicholson, F. H. 1976. Patterned ground formation and description as suggested by low Arctic and subarctic examples. Arctic and Alpine Research, Vol. 8, No. 4, p. 329-42.

Nordenskjöld, O. 1909. Die Polarwelt und ihre Nachbarländer. Leipzig. B. G. Teubner.

Palm, E. 1960. On the tendency towards hexagonal cells. Journal of Fluid Mechanics, Vol. 8, Pt. 1, p. $183-92$.

Price, L. W. 1972. The periglacial environment, permafrost, and man. Association of American Geographers. Committee on College Geography. Resource Paper No. 14.

Ray, R. J. Unpublished. A Rayleigh convection compliant ice front model for sorted patterned ground. |M.S. thesis, University of Colorado, Boulder, Colorado, 1981.]

Richmond, G. M. 1949. Stone nets, stone stripes, and soil stripes in the Wind River Mountains, Wyoming. Journal of Geology, Vol. 57, No. 2, p. 143-53.

Strutt, J. W., third Baron Rayleigh. 1916. On convection currents in a horizontal layer of fluid, when the higher temperature is on the under side. Philosophical Magazine, Sixth Ser., Vol. 32, No. 192, p. 529-46.

Velarde, M. G., and Normand, C. 1980. Convection. Scientific American, Vol. 243, No. 1, p. 92-108.

Washburn, A. L. 1956. Classification of patterned ground and review of suggested origins. Bulletin of the Geological Society of America, Vol. 67, No. 7, p. 823-66.

Washburn, A. L. [ $\left.{ }^{c} 1979.\right]$ Geocryology: a survey of periglacial processes and environments. London, Edward Arnold. [Also published New York, John Wiley and Sons, Inc., [ ${ }^{\mathrm{c}} 1980$ ], with identical pagination.] 